\title{
HUBUNGAN SUPERVISI TERHADAP PELAKSANAAN ASUHAN KEPERAWATAN DI RUMAH SAKIT UMUM DAERAH DR. ZAINOEL ABIDIN BANDA ACEH
}

\author{
Yullyzar $^{1}$, Irfanita Nurhidayah ${ }^{1}$, Nurul Hadisah ${ }^{2}$, \\ ${ }^{1}$ Fakultas Keperawatan Universitas Syiah Kuala \\ ${ }^{2}$ S1 Fakultas Keperawatan Universitas Syiah Kuala \\ *yullyzar@unsyiah.ac.id
}

\begin{abstract}
Abstrak
Supervisi merupakan bagian dari fungsi directing (pengarahan) dalam fungsi manajemen yang berperan untuk mempertahankan agar segala kegiatan yang telah diprogramkan dapat dilaksanakan dengan baik dan lancar. Supervisi secara langsung memungkinkan manajer keperawatan menemukan berbagai hambatan/permasalahan dalam pelaksanaan asuhan keperawatan di ruangan dengan mencoba memandang secara menyeluruh faktor-faktor yang mempengaruhi dan bersama dengan staf keperawatan untuk mencari jalan pemecahannya. Tujuan penelitian ini adalah untuk mengetahui hubungan supervisi terhadap pelaksanaan asuhan keperawatan di Rumah Sakit Umum Daerah dr. Zainoel Abidin Banda Aceh. Jenis penelitian ini adalah deskriptif korelatif melalui pendekatan cross sectional study. Populasi dalam penelitian ini adalah 153 perawat pelaksana di Ruang Rawat Inap Rumah Sakit dr. Zainoel Abidin Banda Aceh. Pengambilan sampel menggunakan teknik total sampling. Metode analisis data menggunakan uji statistic chi-square. Hasil penelitian ada hubungan antara pelaksana supervisi $(\mathrm{p}$-value $=0,002)$, sasaran supervisi ( $p$-value $=0,004)$, frekuensi supervisi ( $p$-value $=0,000)$, tujuan supervisi $(p$-value $=0,002)$ dan teknik supervisi $(\mathrm{p}$-value $=0,000)$ dengan pelaksanaan asuhan keperawatan. Maka dapat disimpulkan bahwa ada hubungan supervisi (p-value $=0,000$ ) terhadap pelaksanaan asuhan keperawatan di Rumah Sakit Umum Daerah dr. Zainoel Abidin Banda Aceh. Saran bagi perawat adalah untuk terus meningkatkan kinerja dalam memberikan asuhan keperawatan kepada pasien.
\end{abstract}

Kata kunci $\quad$ : Pelaksanaan asuhan keperawatan; supervisi; rumah sakit

\begin{abstract}
Supervision is part of the function of directing in management function, that paly a role to maintain all activities that have been programmed can be implemented properly and smoothly. Supervision allows nursing managers directly to find various obstacles/problems of nursing care implementation in ward by trying to look at the overall factors that affect and together with the other nursing staff to find problem solving ways. The purpose of this study was to determine the correlation of supervision to the implementation of nursing care at the dr. Zainoel Abidin Regional General Hospital, Banda Aceh. This research was a correlative descriptive with cross sectional study approach. The population in this study were 153 nurses in patient wards dr. Zainoel Abidin Hospital Banda Aceh. We used total sampling technique. Methods of statistical data analysis was chi-square test. Results of the study showed that there was a correlation between the supervision implementation ( $p$-value $=0.002)$, supervision target $(p$-value $=0.004)$, frequency of supervision $(p$-value $=0.000)$, the purpose of supervision $(p$-value $=0.002)$ and supervision technique $(p$-value $=0.000)$ with the implementation of nursing care. It can be concluded that there was a correlation of supervision ( -value $=0.000$ ) to the implementation of nursing care at the dr. Zainoel Abidin Regional General Hospital Banda Aceh. We suggest for nurses to improve care performance continuously in providing nursing care to patients.
\end{abstract}

Keywords $\quad$ : Nursing care implementation; supervision; hospital 


\section{Pendahuluan}

Asuhan keperawatan adalah satu pendekatan untuk pemecahan masalah yang menghasilkan perawat untuk mengatur dan memberikan asuhan keperawatan. Standar asuhan yang tercantum dalam Standar Praktik Klinis Keperawatan terdiri dari lima fase asuhan keperawatan: 1) Pengkajian; 2) Diagnosis; 3) Perencanaan; 4) Implementasi; dan 5) Evaluasi. Salah satu manfaat dari penerapan asuhan keperawatan yang baik adalah meningkatkan mutu dan kualitas pelayananan dalam bidang keperawatan (Kozier, 2010).

Pelayanan keperawatan yang bermutu tidak sepenuhnya menjadi tanggung jawab perawat pelaksana, kepala ruang selaku manajer mempunyai tanggung jawab terhadap aktifitas asuhan keperawatan dan memfasilitasi perawat pelaksana agar dapat melaksanakan praktek keperawatan sesuai standar (Mustofa, 2008).

Oleh karena itu, pengelolaan pelayanan keperawatan membutuhkan sistem manajerial keperawatan yang tepat untuk mengarahkan seluruh staf keperawatan dalam menghasilkan pelayanan keperawatan yang prima dan berkualitas. Hal ini dapat terlaksanakan dengan dukungan kepala ruang yang mempunyai kemampuan manajerial yang handal untuk melaksanakan fungsi perencanaan, pengorganisasian, pengarahan dan pengendalian aktifitas-aktifitas keperawatan. Fungsi pengarahan dalam proses manajemen dapat dilakukan melalui supervisi oleh seorang manajer, sehingga pelayanan keperawatan yang diberikan berkualitas (Sugiharto, Keliat, \& Sri, 2012).

Supervisi merupakan bagian dari fungsi pengarahan yang berperan untuk mempertahankan agar segala kegiatan yang telah terprogram dapat dilaksanakan dengan baik dan lancar. Supervisi dalam keperawatan bukan hanya sekedar kontrol, akan tetapi lebih dari itu kegiatan supervisi mencakup penentuan kondisi-kondisi atau syarat-syarat yang lazim seperti: individu maupun pengadaan peralatan yang diperlukan untuk tercapainya tujuan asuhan keperawatan secara efektif dan efisien (Marquis \& Huston, 2006).

Kepala ruangan sebagai pelaku utama tercapainya tujuan pelayanan keperawatan di rumah sakit harus mempunyai kemampuan dan keterampilan (skill) dalam melakukan supervisi untuk mendukung pelaksanaan asuhan keperawatan. Pelaksanaan supervisi oleh kepala ruang bertujuan untuk mempertahankan segala kegiatan yang telah dijadwalkan dapat dilaksanakan sesuai standar dan harapan. Supervisi yang dilakukan oleh kepala ruang memerlukan peran aktif semua perawat yang terlibat dalam kegiatan pelayanan keperawatan sebagai mitra kerja yang memiliki ide, pendapat yang perlu didengar, pengalaman yang patut dihargai, dan diikutsertakan dalam proses perbaikan pemberian asuhan keperawatan (Mua, 2011, p. 2).

Kepala ruangan sebagai seorang supervisor juga harus berorientasi pada pekerjaannya dan mempunyai sensitivitas sosial yang mampu memberikan umpan balik, penghargaan, pengakuan serta memotivasi keahlian terhadap stafnya sehingga staf memiliki motivasi yang tinggi dalam memberikan pelayanan keperawatan yang lebih baik (Mua, 2011, p. 3).

Berdasarkan studi penelitian Tampilang (2013, p. 26) menyatakan bahwa kepala ruang melaksanakan supervisi dengan baik sehingga dapat meningkatkan kepuasan kerja perawat pelaksana. Sebaliknya, studi yang dilakukan Wirawan (2013, p. 5) menunjukkan hasil supervisi yang di lakukan kepala ruang kurang baik dapat memberikan dampak pada kinerja perawat, contohnya: uraian kerja mengenai pendokumentasian tidak dilakukan secara optimal oleh staf perawat saat berdinas. 
Berdasarkan hasil wawancara yang dilakukan tanggal 10-13 Maret 2014 dengan 7 orang perawat pelaksana di ruang rawat inap, perawat mengungkapkan peran kepala ruang dalam melakukan supervisi dilaksanakan setiap hari dalam bentuk observasi saja terhadap kinerja perawat. Kepala ruang langsung memberikan teguran apabila perawat melakukan kesalahan dan jarang sekali memberikan reward (pujian) apabila perawat melakukan tugas dengan baik dan apabila mengalami kesulitan/masalah perawat lebih sering mendiskusikan dengan sesama perawat ruangan terlebih dahulu dan sering berkonsultasi kepada perawat senior dibandingkan kepada kepala ruang.

Selanjutnya observasi yang dilakukan peneliti diperoleh data saat melakukan pengkajian keperawatan, staf perawat ruangan melakukan pengkajian keperawatan yang minimal dan menulis data pasien yang dianggap perlu, akan tetapi belum merumuskan diagnosa keperawatan secara lengkap. Hal ini dapat diketahui karena masih ada form pengkajian yang belum terisi lengkap (Head to Toe assessment).

Berdasarkan informasi diatas, peneliti ingin melaksanakan studi penelitian untuk mengetahui hubungan supervisi terhadap pelaksanaan asuhan keperawatan di Rumah Sakit Umum Daerah dr. Zainoel Abidin Banda Aceh. Tujuan dari penelitian ini adalah untuk mengetahui hubungan supervisi terhadap pelaksanaan asuhan keperawatan di Rumah Sakit Umum Daerah dr. Zainoel Abidin Banda Aceh.

\section{Metode}

Desain yang digunakan dalam penelitian ini adalah Deskriptif Korelatif untuk mengetahui hubungan antara variabel independent yaitu supervisi kepala ruang dengan variabel dependent yaitu pelaksanaan asuhan keperawatan oleh perawat pelaksana. Penelitian ini menggunakan pendekatan Cross Sectional Study.

Populasi dari penelitian ini adalah 153 perawat pelaksana yang bertugas di 12 Ruang Rawat Inap Rumah Sakit Umum Daerah dr. Zainoel Abidin Banda Aceh.

Sampel dalam penelitian ini adalah semua perawat pelaksana yang bekerja di Ruang Rawat Inap Rumah Sakit Umum Daerah dr. Zainoel Abidin Banda Aceh dengan kriteria lama bekerja diatas 1 tahun dan sedang tidak mengambil cuti. Berdasarkan kriteria tersebut maka jumlah staf perawat pelaksana yang direkrut menjadi sampel dalam penelitian ini adalah sebanyak 131 orang. Teknik pengambilan sampel dalam penelitian ini menggunakan teknik non probability sampling dengan metode total sampling, dengan cara mengambil semua anggota populasi menjadi sampel (Hidayat, 2009, p.74).

Studi penelitian ini dilakukan di 12 Ruang Rawat Inap Rumah Sakit Umum Daerah dr. Zainoel Abidin Banda Aceh. Adapun alasan pemilihan tempat tersebut karena Rumah Sakit Umum Daerah dr. Zainoel Abidin merupakan rumah sakit rujukan tipe A, di provinsi Aceh dan menjadi rumah sakit pendidikan di provinsi Aceh. Penelitian dilakukan pada 2 Juli - 9 Juli 2015. Instrumen yang digunakan dalam penelitian ini dengan mengunakan kuesioner. Analisa data dalam penelitian ini dilakukan dengan uji Chi Square. 


\section{Hasil}

Tabel 1

Distribusi Karakterisitik Responden berdasarkan usia dan lama bekerja

\begin{tabular}{lccccc}
\hline \multicolumn{1}{c}{ Karakteristik } & Mean & Median & SD & Minimal-Maksimal & 95\% CI \\
\hline Usia & 29,03 & 28 & 4,345 & $22-46$ & $28,28-29,78$ \\
\hline Lama Bekerja & 5,07 & 4 & 3,705 & $1-20$ & $4,43-5,71$
\end{tabular}

Sumber: Data Primer (Diolah 2015)

Berdasarkan tabel 1 menunjukkan ratarata usia responden adalah 29,03 tahun dengan standar deviasi 4,345 tahun. Responden berada pada usia minimal 22 tahun dan masksimal 46 tahun. Rata-rata lama bekerja sekitar 5.07 tahun dengan standar deviasi 3,705 tahun. Responden lama bekerja minimal 1 tahun dan maksimal 20 tahun.

Tabel 2

Distribusi Karakterisitik Responden

\begin{tabular}{|c|c|c|c|}
\hline No & $\begin{array}{r}\text { Karakteristik } \\
\end{array}$ & f & $\%$ \\
\hline \multirow[t]{4}{*}{1} & Jenis Kelamin & & \\
\hline & Laki-Laki & 9 & 6,9 \\
\hline & Perempuan & 122 & 93,1 \\
\hline & Total & 131 & 100 \\
\hline \multirow[t]{5}{*}{2} & Status Perkawinan & & \\
\hline & Menikah & 91 & 69,5 \\
\hline & Belum Menikah & 39 & 29,8 \\
\hline & Janda/Duda & 1 & 0,8 \\
\hline & Total & 131 & 100 \\
\hline \multirow[t]{5}{*}{3} & Tingkat Pendidikan & & \\
\hline & D3 Keperawatan & 87 & 66,4 \\
\hline & S1 Keperawatan & 31 & 23,7 \\
\hline & Ners & 13 & 9,9 \\
\hline & Total & 131 & 100 \\
\hline \multirow[t]{4}{*}{4} & Pengalaman mengikuti seminar manajemen & & \\
\hline & Ada & 71 & 54,2 \\
\hline & Tidak Ada & 60 & 45,8 \\
\hline & Total & 131 & 100 \\
\hline \multirow[t]{13}{*}{5} & Topik seminar yang pernah di ikuti & & \\
\hline & a. Supervisi & 5 & 3,8 \\
\hline & b. Komunikasi & 21 & 16 \\
\hline & c. Kepemimpinan & 17 & 13 \\
\hline & d. Manajemen Konflik & 4 & 3,1 \\
\hline & e. Komunikasi dan Kepemimpinan & 9 & 6,9 \\
\hline & f. Kepemimpinan dan Manajemen Konflik & 3 & 2,3 \\
\hline & g. Supervisi dan Kepemimpinan & 3 & 2,3 \\
\hline & h. Komunikasi dan Manajemen Konflik & & \\
\hline & i. $\quad$ Supervisi dan Komunikasi & 1 & 0,8 \\
\hline & $\begin{array}{ll}\text { j. } & \text { Komunikasi, Kepemimpinan dan } \\
\text { Manajemen Konflik }\end{array}$ & 2 & 1,5 \\
\hline & $\begin{array}{l}\text { k. Supervisi, Komunikasi, Kepemimpinan } \\
\text { dan Manajemen Konflik }\end{array}$ & 6 & 4,6 \\
\hline & Total & 71 & 54,2 \\
\hline
\end{tabular}

Sumber: Data Primer (Diolah 2015) 
Berdasarkan tabel 2 menunjukkan sebanyak 10 orang $(7,6 \%)$ berjenis kelamin laki-laki dan sebanyak 121 orang $(92,4 \%)$ berjenis kelamin perempuan. Sebanyak 91 orang $(69,5 \%)$ menikah dan 39 orang $(29,8 \%)$ belum menikah. Tingkat pendidikan D3 Keperawatan sebanyak 87 orang $(66,4 \%)$, S1 Keperawatan sebanyak 31 orang $(23,7 \%)$ dan Ners sebanyak 13 orang $(9,9 \%)$. Sebanyak 71 orang $(54,2 \%)$ mempunyak pengalaman mengikuti seminar manajemen dan sekitar 60 orang $(45,8 \%)$ tidak mempunyai pengalaman mengikuti seminar manajemen. Dari 71 orang yang mengikuti seminar manajemen sebanyak 5 orang $(3,8 \%)$ dengan topic supervisi, sebanyak 21 orang (16\%) dengan topic komunikasi, sebanyak 17 orang (13\%) dengan topic kepemimpinan, sebanyak 4 orang $(3,1)$ dengan topic manajemen konflik, sebanyak 9 orang $(6,9 \%)$ dengan topic komunikasi dan kepemimpinan, sebanyak 3 orang $(2,3 \%)$ dengan topic kepemimpinan dan manajemen konflik, sebanyak 3 orang $(2,3 \%)$ dengan topic supervise dan kepemimpinan, sebanyak 1 orang $(0,8 \%)$ dengan topic komunikasi dan manajemen konflik, 2 orang $(1,5 \%)$ dengan topic supervise dan komunikasi dan 6 orang $(4,6 \%)$ dengan topic komunikasi, kepemimpinan dan manajemen konflik.

\section{Analisa Bivariat}

Tabel 3

Hubungan Supervisi Dengan Pelaksanaan Asuhan Keperawatan

\begin{tabular}{ccccccccc}
\hline \multirow{2}{*}{ Supervisi } & \multicolumn{9}{c}{ Asuhan Keperawatan } & & \multirow{2}{*}{ Total } & \multirow{2}{*}{ p-value } \\
\cline { 2 - 7 } & \multicolumn{3}{c}{ Baik } & \multicolumn{2}{c}{ Kurang Baik } & & \\
\cline { 2 - 7 } & $\mathrm{f}$ & $\%$ & $\mathrm{f}$ & $\%$ & $\mathrm{f}$ & $\%$ & \\
\hline Baik & 57 & 74 & 20 & 26 & 77 & 100 & 0,000 \\
\hline Kurang Baik & 10 & 18,5 & 44 & 81,5 & 54 & 100 & \\
\hline Jumlah & 67 & 51,1 & 64 & 48,9 & 131 & 100 & \\
\hline
\end{tabular}

Sumber: Data Primer (Diolah 2015)

Berdasarkan pada tabel 3, dapat diketahui bahwa dari 77 responden yang menyatakan supervisi baik, terdapat 57 orang $(74 \%)$ yang memiliki asuhan keperawatan baik, sementara dari 54 responden yang menyatakan supervisi kurang baik, terdapat 44 orang $(81,5 \%)$ yang memiliki asuhan keperawatan kurang baik. Untuk analisa univariat supervisi dan pelaksanaan asuhan keperawatan dapat dilihat di lampiran 20. Melalui uji statistik dengan Continuity Correction, diapatkan bahwa nilai $\mathrm{p}$ value $=0,000$ (Lampiran 20). Berarti $\mathrm{p}$ value $<0,05$ sehingga hipotesa null $(\mathrm{Ho})$ ditolak yang menunjukkan bahwa ada hubungan supervisi terhadap pelaksanaan asuhan keperawatan di Ruang Rawat Inap RSUD Zainoel Abidin Banda Aceh.

Tabel 4

Hubungan Pelaksana Supervisi dengan Pelaksana Asuhan Keperawatan

\begin{tabular}{|c|c|c|c|c|c|c|c|}
\hline \multirow{3}{*}{$\begin{array}{l}\text { Pelaksana } \\
\text { Supervisi }\end{array}$} & \multicolumn{4}{|c|}{ Asuhan Keperawatan } & \multirow{2}{*}{\multicolumn{2}{|c|}{ Total }} & \multirow{3}{*}{$\mathrm{p}$-value } \\
\hline & \multicolumn{2}{|c|}{ Baik } & \multicolumn{2}{|c|}{ Kurang Baik } & & & \\
\hline & $\mathrm{F}$ & $\%$ & $\mathrm{f}$ & $\%$ & $\mathrm{~F}$ & $\%$ & \\
\hline Baik & 61 & 57 & 46 & 43 & 107 & 100 & 0,009 \\
\hline Kurang Baik & 6 & 25 & 18 & 75 & 24 & 100 & \\
\hline Jumlah & 67 & 51,1 & 64 & 48,9 & 131 & 100 & \\
\hline
\end{tabular}

Sumber: Data Primer (Diolah 2015) 
Berdasarkan pada tabel 4, dapat diketahui bahwa dari 107 responden yang menyatakan pelaksana supervisi baik, terdapat 61 orang (57\%) yang memiliki asuhan keperawatan baik, sementara dari 24 responden yang menyatakan pelaksana supervisi kurang baik, terdapat 18 orang $(75 \%)$ yang memiliki asuhan keperawatan kurang baik. Analisa univariat pelaksana supervisi dapat dilihat di lampiran 20.
Melalui uji statistik dengan Continuity Correction, diapatkan bahwa nilai pvalue $=0,009$ (Lampiran 20). Berarti $\mathrm{p}$ value $<0,05$ sehingga hipotesa null (Ho) ditolak, yang menunjukkan bahwa ada hubungan pelaksana supervisi terhadap pelaksanaan asuhan keperawatan di Ruang Rawat Inap RSUD Zainoel Abidin Banda Aceh.

Tabel 5

Hubungan Sasaran Supervisi dengan Pelaksana Asuhan Keperawatan

\begin{tabular}{|c|c|c|c|c|c|c|c|}
\hline \multirow{3}{*}{ Sasaran Supervisi } & \multicolumn{4}{|c|}{ Asuhan Keperawatan } & \multirow{2}{*}{\multicolumn{2}{|c|}{ Total }} & \multirow{3}{*}{$\mathrm{p}$-value } \\
\hline & \multicolumn{2}{|c|}{ Baik } & \multicolumn{2}{|c|}{ Kurang Baik } & & & \\
\hline & $\mathrm{F}$ & $\%$ & $\mathrm{f}$ & $\%$ & $\mathrm{~F}$ & $\%$ & \\
\hline Baik & 50 & 60,2 & 33 & 39,8 & 83 & 100 & 0,011 \\
\hline Kurang Baik & 17 & 35,4 & 31 & 64,6 & 48 & 100 & \\
\hline Jumlah & 67 & 51,1 & 64 & 48,9 & 131 & 100 & \\
\hline
\end{tabular}

Sumber: Data Primer (Diolah 2015)

Berdasarkan pada tabel 5, dapat diketahui bahwa dari 83 responden yang menyatakan sasaran supervisi baik, terdapat 50 orang $(60,2 \%)$ yang memiliki asuhan keperawatan baik, sementara dari 48 responden yang menyatakan sasaran supervisi kurang baik, terdapat 31 orang $(64,6 \%)$ yang memiliki asuhan keperawatan kurang baik. Analisa univariat sasaran supervisi dapat dilihat di lampiran 20. Melalui uji statistik dengan Continuity Correction, diapatkan bahwa nilai $\mathrm{p}$-value $=0,011$ (Lampiran 20). Berarti p-value $<0,05$ sehingga hipotesa null (Ho) ditolak, yang menunjukkan bahwa ada hubungan sasaran supervisi terhadap pelaksanaan asuhan keperawatan di Ruang Rawat Inap RSUD Zainoel Abidin Banda Aceh.

Tabel 6

Hubungan Frekuensi Supervisi dengan Pelaksana Asuhan Keperawatan

\begin{tabular}{|c|c|c|c|c|c|c|c|}
\hline \multirow{3}{*}{$\begin{array}{l}\text { Frekuensi } \\
\text { Supervisi }\end{array}$} & \multicolumn{4}{|c|}{ Asuhan Keperawatan } & \multirow{2}{*}{\multicolumn{2}{|c|}{ Total }} & \multirow{3}{*}{$\mathrm{p}$-value } \\
\hline & \multicolumn{2}{|c|}{ Baik } & \multicolumn{2}{|c|}{ Kurang Baik } & & & \\
\hline & $\mathrm{f}$ & $\%$ & $\mathrm{f}$ & $\%$ & $\mathrm{~F}$ & $\%$ & \\
\hline Baik & 53 & 76,8 & 16 & 23,2 & 69 & 100 & 0,000 \\
\hline Kurang Baik & 14 & 22,6 & 48 & 77,4 & 62 & 100 & \\
\hline Jumlah & 67 & 51,1 & 64 & 48,9 & 131 & 100 & \\
\hline
\end{tabular}

Sumber: Data Primer (Diolah 2015)

Berdasarkan pada tabel 6, dapat diketahui bahwa dari 69 responden yang menyatakan frekuensi supervisi baik, terdapat 53 orang $(76,8 \%)$ yang memiliki asuhan keperawatan baik, sementara dari
62 responden yang menyatakan frekuensi supervisi kurang baik, terdapat 48 orang $(77,4 \%)$ yang memiliki asuhan keperawatan kurang baik. Analisa univariat frekuensi supervisi dapat dilihat di 
lampiran 20. Melalui uji statistik dengan Continuity Correction, diapatkan bahwa nilai $\mathrm{p}$-value $=0,000$ (Lampiran 20). Berarti p-value $<0,05$ sehingga hipotesa null (Ho) ditolak, yang menunjukkan bahwa ada hubungan frekuensi supervisi terhadap pelaksanaan asuhan keperawatan di Ruang Rawat Inap RSUD Zainoel Abidin Banda Aceh.

Tabel 7

Hubungan Tujuan Supervisi dengan Pelaksanaan Asuhan Keperawatan

\begin{tabular}{|c|c|c|c|c|c|c|c|}
\hline \multirow{3}{*}{ Tujuan Supervisi } & \multicolumn{4}{|c|}{ Asuhan Keperawatan } & \multirow{2}{*}{\multicolumn{2}{|c|}{ Total }} & \multirow{3}{*}{$\mathrm{p}$-value } \\
\hline & \multicolumn{2}{|c|}{ Baik } & \multicolumn{2}{|c|}{ Kurang Baik } & & & \\
\hline & $\mathrm{f}$ & $\%$ & $\mathrm{f}$ & $\%$ & $\mathrm{f}$ & $\%$ & \\
\hline Baik & 58 & 58,6 & 41 & 41,4 & 99 & 100 & 0,005 \\
\hline Kurang Baik & 9 & 28,1 & 23 & 71,9 & 32 & 100 & \\
\hline Jumlah & 67 & 51,1 & 64 & 48,9 & 131 & 100 & \\
\hline
\end{tabular}

Sumber: Data Primer (Diolah 2015)

Berdasarkan pada tabel 7, menunjukkan bahwa dari 99 responden yang menyatakan tujuan supervisi baik, terdapat 58 orang $(58,6 \%)$ yang memiliki asuhan keperawatan baik, sementara dari 32 responden yang menyatakan tujuan supervisi kurang baik, terdapat 23 orang $(71,9 \%)$ yang memiliki asuhan keperawatan kurang baik. Analisa univariat tujuan supervisi dapat dilihat di lampiran 20. Melalui uji statistik dengan Continuity Correction, diapatkan bahwa nilai p-value $=0,005$ (Lampiran 20). Berarti p-value < 0,05 sehingga hipotesa null (Ho) ditolak yang menunjukkan bahwa ada hubungan tujuan supervisi terhadap pelaksanaan asuhan keperawatan di Ruang Rawat Inap RSUD dr. Zainoel Abidin Banda Aceh.

Tabel 8

Hubungan Teknik Supervisi dengan Pelaksanaan Asuhan Keperawatan

\begin{tabular}{|c|c|c|c|c|c|c|c|}
\hline \multirow{3}{*}{ Teknik Supervisi } & \multicolumn{4}{|c|}{ Asuhan Keperawatan } & \multirow{2}{*}{\multicolumn{2}{|c|}{ Total }} & \multirow{3}{*}{$\mathrm{p}$-value } \\
\hline & \multicolumn{2}{|c|}{ Baik } & \multicolumn{2}{|c|}{ Kurang Baik } & & & \\
\hline & $\mathrm{F}$ & $\%$ & $\mathrm{f}$ & $\%$ & $\mathrm{f}$ & $\%$ & \\
\hline Baik & 54 & 68,4 & 25 & 31,6 & 79 & 100 & 0,000 \\
\hline Kurang Baik & 13 & 25 & 39 & 75 & 52 & 100 & \\
\hline Jumlah & 67 & 51,1 & 64 & 48,9 & 131 & 100 & \\
\hline
\end{tabular}

Sumber: Data Primer (Diolah 2015)

Berdasarkan pada tabel 8, dapat diketahui bahwa dari 79 responden yang menyatakan teknik supervisi baik, terdapat 54 orang $(68,4 \%)$ yang memiliki asuhan keperawatan baik, sementara dari 52 responden yang menyatakan teknik supervisi kurang baik, terdapat 39 orang (75\%) yang memiliki asuhan keperawatan kurang baik. Analisa univariat teknik supervisi dapat dilihat di lampiran 20 . Melalui uji statistik dengan Continuity Correction, diapatkan bahwa nilai $\mathrm{p}$-value $=0,000$ (Lampiran 20). Berarti p-value < 0,05 sehingga hipotesa null (Ho) ditolak yang menunjukkan bahwa ada hubungan teknik supervisi terhadap pelaksanaan asuhan keperawatan di Ruang Rawat Inap RSUD Zainoel Abidin Banda Aceh. 


\section{Pembahasan}

1. Hubungan Supervisi terhadap Pelaksanaan Asuhan Keperawatan di Ruang Rawat Inap RSUD Zainoel Abidin Banda Aceh

Berdasarkan tabel 1

menunjukkan bahwa usia rata-rata perawat pelaksana adalah 29,03 tahun, dengan standar deviasi 4,345 tahun. Dari hasil estimasi interval dapat disimpulkan bahwa $95 \%$ diyakini rata-rata usia perawat pelaksana adalah diantara 28,28 sampai dengan 29,78 tahun. Berdasarkan Depkes (2009), usia 29,03 tahun termasuk kedalam kategori usia dewasa awal. Menurut Havighurst (1995) dalam (Potter and Perry 2005), salah satu tugas perkembangan pada usia dewasa awal adalah meniti karier dalam rangka memantapkan kehidupan ekonomi rumah tangga. Pada masa ini, individu akan bekerja keras dan bersaing dengan teman sebaya atau kelompok yang lebih tua untuk menunjukkan prestasi kerja yang terbaik untuk memberikan kehidupan yang sejahtera bagi keluarganya. Berdasarkan konsep tersebut dapat disimpulkan bahwa perawat yang berusia dewasa awal mempunyai motivasi kerja yang baik sehingga akan mempengaruhi kinerja perawat dalam memberikan asuhan keperawatan kepada pasien.

Sementara rata-rata lama bekerja perawat pelaksana adalah 5,07 tahun, dengan standar deviasi 3,705 tahun. Dari hasil estimasi interval dapat disimpulkan bahwa 95\% diyakini bahwa rata-rata lama bekerja perawat pelaksana adalah diantara 4,43 sampai dengan 5,71 tahun. Menurut Faizin et al (2008) lama kerja biasanya menyangkut senioritas dan junioritas. Asumsi yang sering berlaku dan diyakini adalah pegawai yang cukup senior dipandang telah memiliki kinerja yang tinggi, sedangkan yang junior perlu dikembangkan dan dibina lagi (Faizin and Winarsih 2008).

Berdasarkan tabel 2 menunjukkan bahwa untuk kategori jenis kelamin, distribusi frekuensi terbanyak adalah perempuan dengan frekuensi sebanyak 122 orang $(93,1 \%)$. Menurut Pribadi (2009), kaum perempuan mempunyai sifat ramah, tekun, disiplin dan teliti dalam pelaksanaan asuhan keperawatan. Sementara untuk kategori status perkawinan, distribusi frekuensi terbanyak adalah responden dengan status menikah sebanyak 91 orang (69,5\%) (Pribadi 2009).

Distribusi frekuensi tertinggi untuk kategori tingkat pendidikan adalah responden dengan tingkat pendidikan D3 Keperawatan yaitu sebanyak 87 orang $(66,4 \%)$. Hal ini dipengaruhi oleh perekrutan dari instansi rumah sakit yang lebih banyak menerima peluang kerja untuk tingkat pendidikan D3 keperawatan.

Frekuensi tertinggi dari kategori pengalaman mengikuti seminar manajemen adalah responden yang ada mengikuti seminar manajemen sebanyak 71 orang $(54,2 \%)$. Salah satu manfaat dari pengadaan seminar manajemen adalah agar dapat membekali perawat pelaksana untuk menjadi pemimpin yang baik, baik untuk dirinya sendiri maupun dalam merawata pasien. Selain itu juga dapat menjadi bekal bagi perawat apabila di masa yang akan datang mereka ditunjuk untuk menjadi kepala ruang. Menurut Mua (2011) Frekuensi tertinggi dari topik seminar manajemen yang pernah diikuti adalah komunikasi yaitu sebanyak 22 orang $(14,7 \%)$.

Berdasarkan pada tabel 5.3, dapat diketahui bahwa dari 77 responden yang menyatakan supervisi baik, terdapat 57 orang (74\%) yang memiliki asuhan 
keperawatan baik, sementara dari 54 responden yang menyatakan supervisi kurang baik, terdapat 44 orang $(81,5 \%)$ yang memiliki asuhan keperawatan kurang baik. Untuk analisa univariat supervisi dan pelaksanaan asuhan keperawatan dapat dilihat di lampiran 20. Melalui uji statistik dengan Continuity Correction, diapatkan bahwa nilai p-value $=0,000$ (Lampiran 20). Berarti pvalue $<0,05$ sehingga hipotesa null (Ho) ditolak yang menunjukkan bahwa ada hubungan supervisi terhadap pelaksanaan asuhan keperawatan di Ruang Rawat Inap RSUD Zainoel Abidin Banda Aceh.

Hasil penelitian yang dilakukan oleh Warsito (2006) menunjukkan bahwa ada hubungan antara persepsi perawat pelaksana tentang fungsi pengarahan kepala ruang dengan pelaksanaan manajemen asuhan keperawatan (Warsito 2006). Studi yang dilakukan oleh Musliadi et al (2014) juga menunjukkan bahwa ada hubungan supervisi dengan pelaksanaan asuhan keperawatan (Musliadi, Syahrir and Haskas 2014).

Berdasarkan hal tersebut peneliti menyimpulkan bahwa suatu keberhasilan pelayanan keperawatan dalam meningkatkan mutu pelayanan tidak terlepas dari peran kepala ruang dalam menjalankan tugasnya yang salah satunya melakukan supervisi sehingga kinerja perawat pelaksana dapat mencapai standar yang telah ditetapkan khususnya dalam memberikan asuhan keperawatan kepada pasien

\section{Hubungan Pelaksana Supervisi terhadap Pelaksanaan Asuhan Keperawatan di Ruang Rawat Inap Rumah Sakit Umum Daerah dr. Zainoel Abidin Banda Aceh}

Hasil analisis Continuity Correction, diapatkan bahwa nilai pvalue $=0,009$. Berarti $\mathrm{p}$-value $<0,05$ sehingga hipotesa null (Ho) ditolak, yang menunjukkan bahwa ada hubungan pelaksana supervisi dengan pelaksanaan asuhan keperawatan di Ruang Rawat Inap RSUD Zainoel Abidin Banda Aceh.

Gillies (1996) menyatakan manajer selaku supervisor harus menjalankan supervisi dengan tepat dalam hal jenis dan kuantitas bagi kelompok kerja yang menjalankannya, karena bila supervisi yang diberikan sangat kurang maka kegiatan pekerja biasa terlalu jauh dari standar kerja yang telah ditetapkan, sebaliknya supervisi yang berlebihan akan menurunkan atau menghambat kreatifitas dan inisiatif pekerja (Gillies 1996).

Berdasarkan konsep dan penelitian yang ada, peneliti menyimpulkan bahwa keberhasilan dalam melaksanakan asuhan keperawatan oleh perawat pelaksana dipengaruhi oleh kepala ruang sebagai yang melakukan supervisi dimana saat supervisi dilaksanakan kepala ruang memberikan pengarahan dan penyelesaian masalah kepada perawat pelaksana bukan untuk mencari kesalahan dari perawat pelaksana.

3. Hubungan Sasaran Supervisi terhadap Pelaksanaan Asuhan Keperawatan di Ruang Rawat Inap Rumah Sakit Umum Daerah dr. Zainoel Abidin Banda Aceh

.Hasil Analisis Continuity Correction, diapatkan bahwa nilai pvalue $=0,011$. Berarti $\mathrm{p}$-value $<0,05$ sehingga hipotesa null (Ho) ditolak, yang menunjukkan bahwa ada hubungan sasaran supervisi dengan pelaksanaan asuhan keperawatan di Ruang Rawat Inap RSUD Zainoel Abidin Banda Aceh. 
Menurut Muninjaya (2004), ada jenis objek pengawasan yaitu objek kualitas dan kuantitas pekerjaan, penggunaan dan pemasukan keuangan, pelaksanaan pekerjaan sesuai dengan rencana kerja, operasional yang dibuat oleh masingmasing staf, serta hal-hal yang bersifat strategis, misalnya instruksi atasan tentang peralatan dan obat-obatan.

Berdasarkan konsep dan penelitian terkait peneliti menyimpulkan bahwa perawat pelaksana yang diberikan tangung jawab dan tugas yang sesuai dengan kemampuannya dapat menumbuhkan rasa percaya diri dalam melaksanakan tugasnya sebagai perawat dalam memberikan asuhan keperawatan, dikarenakan sasaran supervisi yang dilakukan kepala ruang adalah mengatur pekerjaan perawat pelaksana secara adil dan sesuai dengan kemampuan perawat pelaksana dalam memberikan pelayanan keperawatan.

\section{Hubungan Frekuensi Supervisi terhadap Pelaksanaan Asuhan Keperawatan di Ruang Rawat Inap Rumah Sakit Umum Daerah dr. Zainoel Abidin Banda Aceh}

Hasil analisis Continuity Correction, diapatkan bahwa nilai pvalue $=0,000$. Berarti $p$-value $<0,05$ sehingga hipotesa null (Ho) ditolak, yang menunjukkan bahwa ada hubungan frekuensi supervisi terhadap pelaksanaan asuhan keperawatan di Ruang Rawat Inap RSUD Zainoel Abidin Banda Aceh. Andayani (2014) juga mengemukakan dalam penelitiaannya bahwa ada hubunganantara frekuensi supervisi dengan pelaksanaan asuhan keperawatan yang dilakukan oleh perawat pelaksana.

Berdasarkan konsep dan penelitian terkait, peneliti menyimpulkan bahwa tidak ada pedoman yang pasti terkait frekuensi supervisi. Namun apabila kepala ruang menyediakan waktu yang cukup untuk membimbing perawat saat supervisi maka hal ini dapat memperbaiki kinerja perawat dalam memberikan asuhan keparawatan apabila ditemukan masalah atau kesulitan dalam bekerja.

5. Hubungan Tujuan Supervisi terhadap Pelaksanaan Asuhan Keperawatan di Ruang Rawat Inap Rumah Sakit Umum Daerah dr. Zainoel Abidin Banda Aceh

Hasil dari uji statistik dengan Continuity Correction, diapatkan bahwa nilai $\mathrm{p}$-value $=0,005$. Berarti $\mathrm{p}$-value < 0,05 . Ho ditolak yang menunjukkan bahwa ada hubungan tujuan supervisi dengan pelaksanaan asuhan keperawatan di Ruang Rawat Inap RSUD Zainoel Abidin Banda Aceh.

Hasil penelitian ini sesuai dengan penelitian yang dilakukan oleh Riana (2013) yang menyatakan bahwa ada hubungan antara tujuan supervisi dengan kinerja perawat pelaksana. Selain itu supervisi yang baik juga dapat meningkatkan efisiensi kerja sehingga kesalahan yang dilakukan oleh bawahan semakin berkurang(Riana 2013). Berdasarkan konsep dan hasil penelitian diatas, peneliti menyimpulkan bahwa tujuan dilakukan supervisi oleh kepala ruang adalah untuk meningkatkan kinerja perawat pelaksana dalam memberikan asuhan keperawatan sehingga kesalahan yang dilakukan oleh perawat pelaksana semakin berkurang dan kemampuan dalam menjalankan tugasnya semakin meningkat.

6. Hubungan Teknik Supervisi terhadap Pelaksanaan Asuhan Keperawatan di Ruang Rawat Inap Rumah Sakit Umum Daerah dr. Zainoel Abidin Banda Aceh 
Hasil dari analisis Continuity Correction, diapatkan bahwa nilai pvalue $=0,000$. Berarti p-value $<0,05$. Ho ditolak yang menunjukkan bahwa ada hubungan teknik supervisi dengan pelaksanaan asuhan keperawatan di Ruang Rawat Inap RSUD Zainoel Abidin Banda Aceh.

Hal ini sesuai dengan penelitian yang dilakukan oleh Andayani (2014) yang menyatakan bahwa ada hubungan antara teknik supervisi dengan kepuasan kerja perawat pelaksanan (Andayani 2014). Hal yang sama juga di kemukakan oleh Riana et al dalam penelitiannya menyatakan dengan tehnik supervise yang baik akan meningkatkan kinerja perawat (Riana 2013)

\section{Simpulan dan Saran \\ Simpulan}

Berdasarkan hasil penelitian terkait, peneliti menyimpulkan bahwa tehnik supervisi mempunyai hubungan dengan pelaksanaan asuhan keperawatan terutama Teknik supervisi langsung, dikarenakan kepala ruang dapat melihat pekerjaan perawat secara langsung dan apabila ditemukan masalah dapat langsung diselesaikan sekaligus mencari solusi yang terbaik untuk staf perawat.

\section{Saran}

Saran bagi perawat adalah untuk terus meningkatkan kinerja dalam meberikan asuhan keperawatan kepada pasien

\section{Referensi}

Andayani. 2014. Hubungan Supervisi

Kepala Ruang Dengan Kepuasan Kerja Perawat Pelaksana Di RSUD Zainoel Abidin. Banda Aceh. Berggren, I, and E Severinsson. 2008. "Nurse Supervisor Actions in Relation to Their Decision Making
Style and Ethical Approach to Clinical Supervision." J. Advanced Nursing. 41: 615-22.

Cutcliffe, John R., and Kristiina Hyrkäs. 2006. "Multidisciplinary Attitudinal Positions Regarding Clinical Supervision: A Cross-Sectional Study." Journal of Nursing Management 14(8): 617-27.

Davis, C, and L Burke. 2011. "The

Effectiveness of Clinical Supervision for a Group of Ward Managers Based in a District General Hospital: An Evaluative Study." Journal of Nursing Management.

Faizin, A, and Winarsih. 2008. "Hubungan Tingkat Pendidikan Dan Lama Kerja Perawat Dengan Kinerja Perawat Di RSU Pandan Arang Kabupaten Boyolali." Berita Ilmu Keperawatan: 137-42.

Fowler, J. 1996. "The Organization of

Clinical Supervision within the Nursing Profession: A Review of the Literature." Journal of Advanced Nursing 23(3): 471- 478.

Gillies, D.A. 1996. Manajemen

Keperawatan: Suatu Pendekatan Sistem. W.B. Saunders.

Mua. 2011. "Pengaruh Pelatihan Supervisi

Klinik Kepala Ruangan Terhadap Kepuasan Kerja Dan Kinerja Perawat Pelaksana Di Ruang Rawat Inap Rumah Sakit Woodward Palu." FIK Universitas Indonesia.

Musliadi, Syahrir, H., and Y Haskas. 2014.

Hubungan Supervisi Dengan

Pelaksanaan Asuhan Keperawatan

Di Ruang Rawat Inap RSUD Labuang Baji. Makassar.

Van Ooijen, E. 2000. Clinical Supervision:

A Practical Guide. Edinburgh: Churchill Livingstone.

Potter, and Perry. 2005. Buku Ajar 
Fundamental Keperawatan: Konsep, Proses, Dan Praktik. edisi 4. Jakarta: EGC.

Pribadi, Agung. 2009. “Analisis Pengaruh

Faktor Pengetahuan, Motivasi, Dan Persepsi Perawat Tentang Supervisi Kepala Ruang Terhadap Pelaksanaan Dokumentasi Asuhan Keperawatan Di Ruang Rawat Inap RSUD Kelet Provinsi Jawa Tengah Di Jepara." Program Pascasarjana Universitas Diponegoro: 1-100.

Riana. 2013. Hubungan Supervisi Dengan

Kinerja Perawat Pelaksana Di Ruang Rawat Inap Rumah Sakit Dr. Zainoel Abidin Banda Aceh. Banda Aceh.

Shinta, Nindyanto Indah Arini, Niken

Sukesi, and Muslim Argo Bayu Purnomo. 2013. "Pengaruh Supervisi Kepala Ruang Terhadap Dokumentasi Asuhan Keperawatan Di Ruang Rawat Inap Rsud Ungaran." Karya Ilmiah S.1 Ilmu Keperawatan 0(0).

Suara, Mahyar. 2010. Konsep Dasar

Keperawatan. Jakata: Trans Info Medika.

Suyanto. 2008. Mengenal Kepemimpinan

Dan manajemen keperawatan Di Rumah Sakit. Jogjakarta: Mitra Cendikia.

Tampilang, and Warouw Tahuna. 2013.

"Hubungan Supervisi Kepala

Ruangan Dengan Kepuasan Perawat Pelaksana Di RSUD Liunkendage." Jurnal eNERS: 21-26.

Warsito. 2006. "Pengaruh Persepsi Perawat

Pelaksana Tentang Fungsi

Manajerial Kepala Ruang Terhadap Pelaksanaan Manajemen Asuhan Keperawatan Di Ruang Rawat Inap RSJD Dr. Amino Gondohutomo." Universitas Diponogoro. 